\title{
Panorama atual de proteção do direito à terra das comunidades quilombolas e desafios futuros
}

\author{
The current situation of the protection of the quilombolas communities' right \\ to land and its future challenges

\section{La situation actuelle de la protection du droit à la terre de las communautés 'quilombolas' et futurs défis}

Panorama de la situación del derecho a la protección de la tierra de las comunidades 'quilombolas' y retos para el futuro

\author{
Germana Aguiar Ribeiro do Nascimento* \\ (germana_aguiar@hotmail.fr) \\ Mércia Rejane Rangel Batista** \\ (mercia.batista1@gmail.com) \\ Marilia Aguiar Ribeiro do Nascimento*** \\ (mariliaarn@hotmail.com)
}

Recebido em 29/01/2016; revisado e aprovado 29/02/2016; aceito em 15/04/2016

DOI: http:/ / dx.doi.org/10.20435/1984-042X-2016-v.17-n.3(07)

\begin{abstract}
Resumo: A construção da nação brasileira atravessou o período da escravidão, que, ao desaparecer, não incluiu o negro de maneira efetiva na sociedade. Desde o final do século $X X$, as reivindicações desses grupos se tornaram frequentes, gerando uma política compensatória, refletida no contexto legislativo. Nesse sentido, o objetivo deste artigo é examinar a efetividade do direito das comunidades quilombolas aos títulos das terras por elas habitadas. Para isso, a proposta de Emenda Constitucional 215/2000 será analisada.
\end{abstract}

Palavras-chave: comunidades quilombolas; direito à terra; proposta de emenda constitucional 215/2000.

Abstract: The construction of the Brazilian nation went through the period of slavery. Once it was abolished, black people were not included effectively in society. Since the end of the twentieth century, the claims of these groups have become frequent, which generated a compensatory policy, reflected in the legislative context. Therefore, the aim of this article is to examine the effectiveness of the right of these "quilombolas" communities to the titles of lands inhabited by them. To that end the proposed constitutional amendment 215/2000 will be analyzed.

Key words: quilombo communities; right to land; proposed constitutional amendment 215/2000.

Résumé: La construction de la nation brésilienne a traversé la période de l'esclavage, qui, à disparaître, n'a pas compris les noirs efficacement dans la société. À partir de la fin du XXe siècle, les revendications de ces groupes se sont devenues fréquentes, ce qui a généré une politique compensatoire, prise en compte dans le contexte législatif. L'objectif de cet article est d'examiner l'efficacité du droit de las communautés "quilombolas" aux titres des terres habitées par eux. Pour cela, la proposition d'amendement constitutionnel 215/2000 será analysée.

Mots-clés: communautés quilombolas; droits fonciers; proposition d'amendement constitutionnel 215/2000.

Resumen: La construcción de la nación brasileña pasó por el período de la esclavitud, que, al desaparecer, no incluió el negro de manera efectiva en la sociedad. Desde finales del siglo XX, los reclamos de estos grupos se hicieron frecuentes, lo que llevó a una política compensatoria, que se refleja en el marco legislativo. Por consiguiente, el propósito de este artículo es examinar la efectividad del derecho de las comunidades quilombolas a los títulos de las tierras que habitan. Para ello, la propuesta de Enmienda Constitucional 215/2000 sera analizada.

Palabras clave: comunidades quilombolas; derechos sobre la tierra; propuesta de enmienda constitucional 215/2000.

\footnotetext{
* Universidad de Valencia, Valencia, Espanha.

** Universidade Federal de Campina Grande (UFCG), Campina Grande, Paraíba, Brasil.

*** Faculdades Integradas de Patos (FIP), Patos, Paraíba, Brasil.
} 


\section{INTRODUÇÃO}

O Brasil utilizou, durante séculos, a mão de obra escrava, discriminando o negro e subordinando-o a várias formas de degradação. Ao longo do tempo, essa parcela da população criou núcleos de resistência, através de movimentos de luta pela garantia de seus direitos, tanto antes quanto após a abolição da escravatura, que ocorreu apenas em 1888, haja vista que esta não gerou a sua efetiva inserção na sociedade brasileira. Uma dessas formas de resistência era o quilombo, no qual os negros viam a possibilidade de se reproduzirem e se manterem física, social e culturalmente face ao sistema escravista.

Contemporaneamente, as comunidades quilombolas lutam pelo direito ao título de suas terras, em consonância com a inserção do artigo 68, no Ato das Disposições Constitucionais Transitórias, na Constituição da República Federativa do Brasil de 1988, que implica uma outra forma de luta e resistência.

Para os quilombolas, a terra adquire um particular significado, já que se constitui como instrumento que mantém a coesão social do grupo, permitindo a sua reprodução, como também a preservação da cultura, dos valores e do modo particular de vida dentro das comunidades ${ }^{1}$. Além disso, constitui-se como a consagração do direito fundamental de moradia, previsto no art. $6^{\circ}$ do texto constitucional, em respeito ao princípio da dignidade da pessoa humana, fundamento axiológico da República Federativa do Brasil.

Por força do Decreto n. 4.887, de 2003, o Instituto Nacional de Colonização e Reforma Agrária (INCRA) é o órgão responsável, na esfera federal, pela titulação

\footnotetext{
${ }^{1}$ Como exemplos dessa situação e os desdobramentos, tantos em termos de compreensão no plano do direito, da antropologia, como também nos estudos de caso, pode-se sugerir, dentre outros, os textos de Almeida (2002), Araújo e Batista (2013), Batista (2013) e Nascimento (2011).
}

dos territórios quilombolas. Analisandose o sítio eletrônico desse instituto, observa-se que foram emitidos 154 títulos, regularizando $1.007 .827,8730$ hectares em benefício de 127 territórios, 217 comunidades e 113.145 famílias quilombolas². Há, ainda, junto ao INCRA, 1.290 processos em aberto em todas as superintendências regionais, à exceção de Roraima, MarabáPA e Acre, além de demandas que ainda não foram formalmente submetidas.

Esses dados parecem sugerir que há, no cenário atual, plena efetividade do direito à terra por essas comunidades. Entretanto, no âmbito legislativo, encontra-se em tramitação a Proposta de Emenda Constitucional 215/2000 e, apensada a ela, a Proposta de Emenda Constitucional 161/2007 que visa modificar a redação do artigo 68 do Ato das Disposições Constitucionais Transitórias e a da Ação Direta de Inconstitucionalidade n. 3.239 movida pelo Partido Democratas que requer a inconstitucionalidade do Decreto n. 4.887/ 2003 que podem implicar em sérios reflexos na realização do referido direito.

Nesse contexto, o objetivo do presente artigo é analisar o panorama atual referente à proteção do direito das comunidades quilombolas aos títulos das terras por elas habitadas, examinando as perspectivas futuras em termos legislativos para efetivação plena deste direito no contexto brasileiro. Para isso, inicialmente, observa-se, em que medida o referido direito é protegido pelo ordenamento jurídico brasileiro, destacando-se o procedimento de regularização de titulação das terras dessas comunidades, para, ao final, identificar os desafios futuros para implementação desse direito dos quilombolas diante da Proposta de Emenda Constitucional 215/2000 e, apensada a ela, a Proposta de Emenda Constitucional 161/2007. A investigação tem caráter

\footnotetext{
${ }^{2}$ Disponível em: <http://www.incra.gov.br/ quilombola>. Acesso em: 30 out. 2015.
} 
qualitativo, partindo da análise de documentos atinentes à legislação nacional, à jurisprudência e à literatura especializada acerca do tema.

\section{TRATAMENTO LEGAL DA QUESTÃO QUILOMBOLA}

Em termos teóricos, a questão quilombola implica políticas de construção de identidade. Trata-se de um cenário no qual se verificam movimentos mais amplos no interior de Estados nacionais, junto com os novos ordenamentos jurídicos nacionais latino-americanos, encaixando-se na luta pelos chamados "direitos étnicos" ${ }^{3}$, direitos sociais, direitos trabalhistas.

A partir da década de 1960, discute-se a natureza contrastiva e relacional da identidade étnica (BARTH, 1997; CARDOSO DE OLIVEIRA, 1976), consolidando-se então uma crítica aos conceitos de assimilação e aculturação, posto que traz consigo a ideia de que as diferenças culturais podem permanecer, apesar dos contatos interétnicos e da interdependência dos grupos, e que as sociedades se distinguem mais pelo contato do que pelo isolamento.

F. Barth (2000), ao chamar a atenção para a importância de se estudar a partir das fronteiras, destaca que é no fluxo de pessoas que as distinções de categorias étnicas se conformam. E é, ao observar as fronteiras, não apenas física, como também, sociais e politicas, que se apreendem

\footnotetext{
${ }^{3}$ No caso do Brasil, em 1988, quando as lutas pela redemocratização do país desembocaram na Constituinte, ocasião em que também se comemorava os 100 anos de libertação dos escravos, foi criada a oportunidade política catalisada pelos movimentos negros e pelos intelectuais orgânicos no sentido de garantir o reconhecimento de direitos específicos a comunidades negras rurais com a inclusão do Art. 68, das Disposições Transitórias, que diz: "Aos remanescentes das comunidades de quilombos que estejam ocupando suas terras é reconhecida a propriedade definitiva, devendo o Estado emitir-lhes os títulos respectivos".
}

os processos de construção de identidades e novos sujeitos políticos nos contextos rurais em estudo.

Assim, mais recentemente na história do Brasil, houve uma intensificação de processos reivindicativos plasmados por populações rurais, com uma ênfase na questão territorial, indicando aí um cenário de lutas e disputas concretas e simbólicas em torno da noção da identidade e do território ocupado ou percebido enquanto legítimo.

É o caso de grupos rurais negros, que passam a ser vistos e também a se enunciarem enquanto parte do conjunto classificado como "remanescentes de quilombos". Trata-se aqui da criação de novos sujeitos políticos, que, ao 'emergirem', impõem uma discussão crítica e uma expansão no campo de estudos sobre populações rurais ${ }^{4}$. Esses novos sujeitos passam a exigir também mudanças legislativas.

Nesse sentido, em 1988, foi promulgada a Constituição da República Federativa do Brasil, que pela primeira vez, contemplou direitos e garantias visando à proteção dos negros, como consequência, sobretudo, das várias ações realizadas pelo Movimento Negro, inaugurando, assim, uma nova época de reflexão acerca dos direitos humanos.

Assim, na Seção II, do Capítulo III, do Título VIII, nos artigos 215 e 216, da Constituição Brasileira, registrou-se que os grupos afro-brasileiros são formadores do processo civilizatório nacional; determinou-se o tombamento de todos os documentos e os sítios detentores de reminiscências históricas dos antigos quilombos; estabeleceu-se que o Poder Público, com a colaboração da comunidade, deve promover e proteger o patrimônio cultural brasileiro, por meio de inventários, registros, vigilância, tombamento e desapropriação, e de outras formas de acau-

\footnotetext{
${ }^{4}$ Ver no aspecto teórico e etnográfico Arruti (2006) e nas discussões sobre o poder enunciador e performativo do Estado Bourdieu (2004).
} 
telamento e preservação; dentre outros direitos e garantias:

Art. 215. O Estado garantirá a todos o pleno exercício dos direitos culturais e acesso às fontes da cultura nacional, e apoiará e incentivará a valorização e a difusão das manifestações culturais. $1^{\circ}$. O Estado protegerá as manifestações das culturas populares, indígenas e afro-brasileiras, e de outros grupos participantes do processo civilizatório nacional. $2^{\circ}$. A lei disporá sobre a fixação de datas comemorativas de alta significação para os diferentes segmentos étnicos nacionais.

Art. 216. Constituem patrimônio cultural brasileiro os bens de natureza material e imaterial, tomados individualmente ou em conjunto, portadores de referência à identidade, à ação, à memória dos diferentes grupos formadores da sociedade brasileira, nos quais se incluem:

I - as formas de expressão;

II - os modos de criar, fazer e viver;

III - as criações científicas, artísticas e tecnológicas;

IV - as obras, objetos, documentos, edificações e demais espaços destinados às manifestações artístico-culturais;

$\mathrm{V}$ - os conjuntos urbanos e sítios de valor histórico, paisagístico, artístico, arqueológico, paleontológico, ecológico e científico.

Com efeito, Souza (2008) afirma que a Constituição de 1988 representa um divisor de águas ao incorporar em seu conteúdo o reconhecimento de que o Brasil é um Estado pluriétnico e de que há outras percepções e usos da terra para além da lógica de terra privada e o direito à manutenção da cultura e dos costumes dos povos aqui viventes. É, inclusive, a relação desses povos com as terras ocupadas, nas quais há a difusão de sua cultura, seus modos de criar, fazer e viver critério hábil para defini-la como quilombola, segundo Carlos Ari Sundfeld (2002).

Nesse contexto, garante o direito das comunidades quilombolas, ao dispor no artigo 68 do Ato das Disposições Constitucionais Transitórias que "Aos remanescentes das comunidades de quilombos que estejam ocupando suas terras é reconhecida a propriedade definitiva, devendo o Estado emitir-lhe os títulos respectivos", constituindo-se, portanto, previsão do estabelecimento de uma política compensatória aos remanescentes de quilombos que ainda continuem em suas terras, após tanto tempo de subordinação. Trata-se de norma de eficácia plena, não necessitando, portanto, de outra para que tenha validade no plano prático.

Para O'Dwyer (2002, p. 14), “o texto constitucional não evoca apenas uma identidade histórica que pode ser assumida e acionada na forma da lei". Faz-se necessário que esses sujeitos históricos presumíveis existam no presente e tenham como condição básica o fato de ocupar uma terra que, por direito, deverá ser em seu nome titulada, como dispõe o art. 68 do ADCT da Constituição Federal de 1988.

Reconhece, assim, a propriedade das terras das comunidades remanescentes de quilombos, garantindo que esse direito seja efetivado através do processo administrativo e judicial, cuja sentença será declaratória com efeitos retroativos "ab ovo", desde o início, já que o direito subjetivo já existia antes mesmo da promulgação constitucional.

Em termos jurídicos, sustenta-se que, embora o direito aos títulos de terras dos remanescentes de quilombos não se encontre no Título II, Dos Direitos e Garantias Fundamentais, na Carta Magna, trata-se de um direito constitucional fundamental, pois visa garantir a dignidade da pessoa humana, sendo, doravante, indispensável para uma vida digna e sem distinções. Além disso, o artigo quinto, 
parágrafo segundo, da Constituição Federal estabelece que os direitos e garantias expressos na Constituição não excluem outros decorrentes do regime e dos princípios por ela adotados, ou dos tratados internacionais em que a República Federativa do Brasil seja parte.

Segundo o Procurador Federal Leandro Mitidieri de Figueiredo (2011), o direito conferido aos remanescentes de quilombos é um direito coletivo, fundamental de segunda geração, tendo em vista que se refere à igualdade e à justiça social, correspondendo a uma finalização do processo de abolição, compensando os erros da história do país. A Procuradora Federal Luciana Job (2006) afirma, todavia, que se trata de um direito de segunda e terceira geração, e ainda, na prática, de quarta geração :

Os direitos postos no conteúdo do artigo 68 do ADCT são categorizados como direitos de segunda e terceira geração. São interesses e direitos difusos, divididos em: direitos socioeconômicos, que buscam a melhoria das condições de vida e de trabalho do povo brasileiro, por meio de uma obrigação de fazer do Estado, bem como direito de ou à fraternidade, decorrentes de uma sociedade de massa [...]. Mas, de fato, são direitos de quarta geração já englobalizados que envolvem o direito à democracia, à informação e ao pluralismo.

Na verdade, percebe-se que, apesar de já estar previsto, tal direito teve sua efetividade mitigada pela elite conservadora brasileira. Durante os governos de José Sarney (1985-1990), Fernando Collor (1990-1992), Itamar Franco (1993-1994) e Fernando Henrique Cardoso (1994-2002), os quilombolas tiveram seus direitos restringidos pela edição de portarias e decretos que limitavam a efetivação do artigo 68 da Constituição Federal de 1988. Entretanto, durante o governo de Luiz
Inácio Lula da Silva, adveio o Decreto n. $4887 / 2003$, que regulamentou o procedimento para identificação, reconhecimento, delimitação, demarcação e titulação das terras ocupadas por remanescentes das comunidades de quilombos, ou seja, quase após duas décadas sem que o artigo 68 se tornasse concretamente eficaz, trazendo doravante avanços expressivos. $\mathrm{O}$ artigo 17 do Decreto n. 4887/03 prevê que o título das terras será inalienável, indisponível, imprescritível e impenhorável, como também indivisível, tendo em vista o caráter coletivo dos remanescentes.

Todavia esse Decreto começou a ser alvo de protesto por parte de vários empresários e políticos, o que acarretou, na prática, uma série de dificuldades para a aplicação desses direitos. Deveria ter sido editado, no prazo de sessenta dias, um regulamento para que se começassem os processos de identificação, reconhecimento e titulação das terras, mas só houve a edição, em 2004, da Instrução Normativa n. 16.

Ocorre que, na prática, a Instrução Normativa n. 16 não trouxe grandes avanços no processo, razão pela qual, em 2005, o INCRA a revogou e regulamentou a questão através da Instrução Normativa n. 20, que passou a exigir o principal instrumento de reconhecimento das comunidades quilombolas, qual seja, o Relatório Técnico de Identificação e Delimitação, denominado de relatório antropológico.

Assim, com a assinatura do convênio da Fundação Cultural Palmares, um grupo de antropólogos assumiu a tarefa de produção de laudos de identificação étnica e territorial (ARRUTI, 2006). Se antes quilombo estava associado ao universo histórico ou se era uma categoria constituída pelo debate urbano de lideranças políticas, agora o cenário é bastante diversificado, pois se trata de uma categoria de reconhecimento político e que corresponde a direitos diferenciados. Por essa razão, Almeida (2002) discute com profundidade as acepções contidas no termo e indica 
a pertinência da reflexão antropológica, que permite recuperá-la enquanto uma categoria de autoatribuição, implicando processos distintos de territorialização ${ }^{5}$.

Desde então, houve um número crescente de estudos realizados em todo o país, quase sempre atendendo a uma demanda estatal, pois a necessidade de proceder à regularização fundiária de tais comunidades torna imprescindível a elaboração de relatórios antropológicos de regularização fundiária. Contudo o exercício de trabalhos por encomenda não implica a ausência de exigências acadêmicas. Trata-se de um cenário que permite investigar o que existe de antropologia nos relatórios encomendados pelo INCRA, do mesmo modo que já se indagou o que existira de antropologia nas perícias antropológicas (OLIVEIRA, 1994). Apesar do número crescente de estudos, vários processos ficaram paralisados em decorrência da falta de antropólogos para a elaboração dos relatórios, bem como do tempo exigido para a feitura de tal instrumento.

Em setembro de 2008, foi publicada a Instrução Normativa n. 49/2008, com o intuito de regularizar a titulação das terras quilombolas, contemplando, novamente, um processo moroso e burocrático, que compromete a efetivação de um direito garantido pela própria Constituição Federal. Atualmente, encontra-se, em vigor, a Instrução Normativa n. 57, de outubro de 2009.

Assim, a partir dessa exigência constitucional, o Estado brasileiro não pôde se abster e teve que regularizar o procedimento para beneficiar as comunidades quilombolas, para isto, o Presidente da República editou, consoante o artigo 84, incisos IV e VI, alínea a, da Constituição Federal, o supracitado Decreto n. 4.887/03.

Importante destacar que, após o advento da Constituição Federal e a partir do I Encontro Nacional das Comunidades

\footnotetext{
${ }^{5}$ Ver Barth (1997) ou Oliveira (1998).
}

Negras Rurais, realizado em Brasília, DF, em 1995, e da I e da II Reuniões da Comissão Nacional das Comunidades Rurais Quilombolas, realizadas em Bom Jesus da Lapa, na Bahia e em São Luís do Maranhão, percebeu-se um crescimento das mobilizações quilombolas para reconhecimento de suas terras também no âmbito regional. Segundo Almeida (2002, p. 73), “o movimento quilombola vai consolidando uma dimensão nacional e constituindo-se num interlocutor indispensável nos antagonismos sociais que envolvem aquelas territorialidades específicas", o que culminou na previsão do reconhecimento e legalização, na forma da lei, das terras ocupadas por comunidades remanescentes de quilombos também em Constituições estaduais, a exemplo da Constituição do Estado da Bahia e na Constituição do Estado do Maranhão.

\section{PROCEDIMENTO DE REGULARIZAÇÃO DA TITULAÇÃO DAS TERRAS DAS COMUNIDADES REMANESCENTES DE QUILOMBOS}

O Decreto n. 4.887/03 estabelece que o início do procedimento pode ocorrer de ofício pelo Incra ou por requerimento de qualquer comunidade que se autoidentifique como descendente de quilombos. Já o parágrafo quarto do artigo terceiro do decreto mencionado prevê ainda que a adjetivação será inscrita no Cadastro Geral junto à Fundação Cultural Palmares, que tem a incumbência de expedir a certidão desse ato. Além disso, o parágrafo primeiro do mesmo artigo prevê que o INCRA deverá regulamentar os procedimentos administrativos para identificação, reconhecimento, delimitação, demarcação e titulação das terras ocupadas pelos remanescentes das comunidades dos quilombos, dentro de sessenta dias da publicação do decreto. Destarte, retorna ao INCRA a responsabilidade de regularização dessas terras, tendo em vista que, em 1999, tal competência era do Ministério da Cultura. 
Como já mencionado, atualmente, aplica-se a Instrução Normativa n. 57/2009, publicada pelo INCRA, que regulamenta o referido procedimento.

O processo poderá ser aberto de ofício pelo INCRA, ou pela solicitação de qualquer interessado, de entidades ou associações representativas, conforme afirma o artigo sétimo da referida Instrução Normativa. Exige-se, para o início do processo, que as comunidades estejam cadastradas no Cadastro Geral de Remanescentes de Comunidades Quilombolas da Fundação Cultural Palmares (FCP), na qual devem obter uma certidão.

Alguns procedimentos são necessários para a emissão da Certidão da Fundação Palmares, quais sejam: apresentação da ata de assembleia na qual a comunidade aprova sua qualidade de quilombola e um relato da história da comunidade, podendo ainda ser exigida uma visita à comunidade com o escopo de obter mais informações e esclarecer eventuais questionamentos.

Na Instrução Normativa em questão, o INCRA estabelece que o relatório antropológico constitui peça fundamental para o processo de identificação. Assim, consoante o artigo 10, inciso I, da referida Instrução, tal relatório conterá uma caracterização histórica, econômica e sociocultural do território quilombola identificado. Conterá, ainda, informações sobre as terras e as edificações que englobem espaços de moradia, as fontes terrestres, fluviais, lacustres ou marítimas de subsistência da população, as terras e as edificações destinadas aos cultos religiosos, dentre outras informações pertinentes.

O Ministério Público Federal designa que a Associação Brasileira de Antropologia (ABA) indique peritos para que os relatórios antropológicos, laudos, sejam efetivados. Logo, tais profissionais realizam pesquisas nas populações, elaborando laudos chamados de Relatório
Técnico de Identificação e Delimitação (RTID), que serão utilizados no processo de identificação das comunidades.

A partir da emissão da certidão, o perito poderá começar a elaborar o seu Relatório, identificando o território quilombola e demonstrando a sua demanda fundiária. Durante a feitura dos relatórios, as comunidades terão o direito de serem informadas acerca do trabalho realizado; a preservação de sua intimidade, de acordo com seus padrões culturais; o direito de autorizarem para que as informações relatadas nos relatórios sejam utilizadas em outros meios, e acesso aos resultados dos levantamentos realizados, consoante o artigo sétimo dessa norma. Os RTIDs são ainda de responsabilidade da Superintendência Regional do INCRA, consoante o artigo $9^{\circ}$ :

A identificação dos limites das terras das comunidades remanescentes de quilombos a que se refere o art. $4^{\circ}$, a ser feita a partir de indicações da própria comunidade, bem como a partir de estudos técnicos e científicos, inclusive relatórios antropológicos, consistirá na caracterização espacial, econômica, ambiental e sociocultural da terra ocupada pela comunidade, mediante Relatório Técnico de Identificação e Delimitação - RTID, com elaboração a cargo da Superintendência Regional do INCRA, que o remeterá, após concluído, ao Comitê de Decisão Regional, para decisão e encaminhamentos subseqüentes.

Nota-se, doravante, que alguns documentos constarão do Relatório Técnico de Identificação e Delimitação, como o cadastramento das famílias quilombolas, o parecer técnico e jurídico, a planta e o memorial descritivo, que deverão ser remetidos ao Comitê de Decisão Regional. Esse órgão tem competência para analisar e decidir se o laudo está de acordo com as exigências estabelecidas para sua 
elaboração. Se o relatório for aprovado, será encaminhado para publicação, que ocorrerá duas vezes consecutivas no Diário Oficial da União e no Diário Oficial da Unidade da Federação; caso o laudo não seja aprovado, o Comitê devolverá o relatório para o Coordenador do Grupo Técnico Interdisciplinar para sua revisão ou complementação. Nesse sentido, o parágrafo quarto, do artigo 11, da Instrução Normativa prevê que:

Na hipótese de o RTID concluir pela impossibilidade do reconhecimento da área estudada como terra ocupada por remanescente de comunidade de quilombo, o Comitê de Decisão Regional do INCRA, após ouvidos os setores técnicos e a Procuradoria Regional, poderá determinar diligências complementares ou, anuindo com a conclusão do Relatório, determinar o arquivamento do processo administrativo.

No caso de aprovação, concomitantemente à publicação, o RTID deverá ser enviado aos órgãos e entidades, tais quais: Instituto do Patrimônio Histórico e Artístico Nacional (IPHAN), o Instituto Brasileiro do Meio Ambiente e dos Recursos Naturais Renováveis (IBAMA), a Fundação Nacional do Índio (FUNAI), a Fundação Cultural Palmares (FCP); Secretaria do Patrimônio da União (SPU); Serviço Florestal Brasileiro (SFB) etc. Tal procedimento é necessário, pois, se as terras da comunidade estiverem inseridas em territórios administrados por algum desses órgãos, outros atos far-se-ão necessários.

O parágrafo terceiro do artigo 12, da mencionada Instrução Normativa estabelece que será dada anuência tácita ao relatório, se em trinta dias tais órgãos não se manifestarem, sendo dada assim a titularidade das terras. Os interessados terão o prazo de noventa dias, após a publicação e as notificações, para contestarem o RTID junto à Superintendência Regional do INCRA, juntando as provas pertinentes.
Cabe mencionar que, se as terras incidirem sobre terras devolutas da União, não haverá maiores dificuldades para a titulação. Todavia, se incidirem sobre terrenos da marinha, marginais de rios, ilhas e lagos, deverá ocorrer uma atuação conjunta entre o INCRA e a Secretaria de Patrimônio da União, tomando as medidas cabíveis para a emissão do título. Deve-se utilizar da regra da especialidade, em decorrência do princípio de que, ao determinar quais serão os bens públicos da União no artigo 20; dos Estados, no artigo 26 e dos municípios de forma residual, a Constituição Federal traça normais gerais.

Em contrapartida, se as terras estiverem localizadas em unidades de conservação constituídas, áreas de segurança nacional, faixa de fronteira e em terras indígenas, o INCRA, o IBAMA, a Secretaria Executiva do Conselho de Defesa Nacional, a FUNAI e a Fundação Cultural Palmares atuarão de modo conjunto com o escopo de tomar medidas que conciliem os interesses das comunidades com os interesses do Estado, devendo ser observadas, quanto às unidades de conservação a Lei 9.985/2000.

As propriedades das comunidades remanescentes de quilombos são especiais e devem preponderar frente a um conflito de interesses com normas gerais. O procurador federal Leandro Mitidieri Figueiredo (2011) sustenta: "Ademais, a lei expressamente prevê a possibilidade de titulação de bens públicos às comunidades tradicionais" (art. 79, parágrafo quinto, Decreto-Lei n. 9760/46 acrescentado pela MP n. 292/06).

Cabe ainda destacar o que determina o artigo 13, do Decreto n. 4.887/2003:

Incidindo nos territórios ocupados por remanescentes das comunidades dos quilombos título de domínio particular não invalidado por nulidade, prescrição ou comisso, e nem tornado ineficaz por outros fundamentos, será realizada vistoria e avaliação 
do imóvel, objetivando a adoção dos atos necessários à sua desapropriação, quando couber.

Destarte, nesses casos, onde existe título legítimo de propriedade das terras ocupadas, o meio legal deverá ser a desapropriação do imóvel pelo Poder Público, para que se possa, em seguida, dar o título às comunidades. $\mathrm{O}$ artigo quinto, em seu inciso XXIV, da Carta Magna, afirma que se a comunidade viver no campo (algo que se dá na maioria dos casos das comunidades quilombolas), ocorrerá a desapropriação em virtude do interesse social, consoante o artigo segundo da Lei 4.132/1962, que considera o interesse social, o estabelecimento e a manutenção de colônias ou cooperativas de povoamento ou do trabalho agrícola. Faz-se evidente que uma comunidade quilombola rural encaixa-se nessa definição, devendo, pois, ser preservada.

Já o artigo 14 do Decreto 4.887/2003 aduz que, se for verificada a presença de ocupantes nas terras dos remanescentes das comunidades dos quilombos, o INCRA acionará os dispositivos administrativos e legais para o reassentamento das famílias de agricultores pertencentes à clientela da reforma agrária ou a indenização das benfeitorias de boa-fé, quando couber, seguindo assim, os dispositivos do Código Civil Brasileiro, em seus artigos 1214 a 1220.

Enfim, somente com a publicação do presidente do INCRA reconhecendo e declarando os limites da terra quilombola, o processo será encerrado. $\mathrm{O}$ presidente terá o prazo de trinta dias para publicar a portaria no Diário Oficial da União e da unidade federativa onde está situado o quilombo.

Ademais, o artigo 24 da Instrução Normativa 49/2008 afirma que o Presidente do INCRA realizará a titulação mediante a outorga de título coletivo e pró-indiviso à comunidade, em nome de sua associação legalmente instituí$\mathrm{da}$, sem nenhum ônus financeiro e com obrigatória inserção das cláusulas de inalienabilidade, imprescritibilidade e de impenhorabilidade, devidamente registradas no Serviço Registral da Comarca de localização das áreas. Assim, percebe-se que as comunidades devem formar associações para que as representem, sendo obrigadas a inscrever seus estatutos no registro competente, somente adquirindo personalidade jurídica desse modo, conforme o caput dos artigos 45 e 54 do Código Civil Brasileiro, tendo, a partir daí, a possibilidade de serem titulares de direito, qual seja, o da propriedade das terras.

Nota-se, pois, que os títulos de domínio não serão entregues individualmente, haja vista tratar-se de uma identidade coletiva, devendo conter, além do local onde os integrantes moram, os locais utilizados para a reprodução econômica, como também os espaços usados para atividades religiosas, ou seja, todos os ambientes necessários para a reprodução física, socioeconômica e cultural, com o objetivo de preservar a identidade cultural.

Constando no título as cláusulas de inalienabilidade, imprescritibilidade e impenhorabilidade, observa-se um caráter sui generis da propriedade, pois todos poderão usufruir e usar da terra de maneira coletiva, ficando a associação impedida de dispor do bem; logo, a propriedade não poderá ser oferecida como garantia nem sofrer constrição judicial, não estando sujeitas à usucapião.

\section{PERSPECTIVAS FUTURAS DE REALIZAÇÃO DO DIREITO À TERRA DAS COMUNIDADES QUILOMBOLAS}

APropostadeEmenda Constitucional 215/2000 apresentada pelo deputado federal Almir Sá e outros visa acrescer o inciso XVIII ao artigo 49 , modificar o $\S 4^{\circ}$ e acrescentar o $\$ 8^{\circ}$, ambos no artigo 231, da Constituição da República Federativa do Brasil. Nesse sentido, tem por objetivo 
incluir dentre as competências exclusivas do Congresso Nacional a aprovação de demarcação das terras tradicionalmente ocupadas pelos índios e quilombolas, e a ratificação das demarcações já homologadas, estabelecendo que os critérios e procedimentos de demarcação serão regulamentados por lei.

Portanto a PEC 215 é uma Proposta de Emenda Constitucional que tem por intento dar aos parlamentares o poder de criar e também anular demarcações de terras indígenas, quilombolas e unidades de conservação, incumbência, hodiernamente, do Poder Executivo de demarcar Áreas Protegidas.

Como observado, é o Poder Executivo que tem estrutura e condições técnicas para cumprir o procedimento necessário à demarcação, com equipes capacitadas para realizar estudos de comprovação da ocupação tradicional e de solucionar conflitos e a eventual necessidade de indenizações. Com a PEC 215, busca-se, então, transferir a palavra final acerca de demarcação das terras das comunidades e das unidades de conservação do Executivo para a Câmara dos Deputados.

Trata-se de um cenário que ignora ou menospreza todo o caminho que foi sendo trilhado, especialmente no âmbito nacional, em consonância com o Direito Internacional, no qual se reconhece a existência de direitos diferenciados e coletivos, e da legitimidade do conhecimento do perito. Nesse caso específico, tanto no que diz respeito aos direitos indígenas como também quilombolas, tem-se reconhecido a competência dos antropólogos para, a partir da perícia na produção do conhecimento, tornar compreensível (traduzir) os saberes e os modos próprios de construção de um universo simbolicamente constituído, de modo a garantir esse direito.

A proposta legislativa nega a possibilidade de existir diversidade no interior do Estado-Nação e que esta se acessa através da prática antropológica. Nesse caso, é através do trabalho de campo, do diálogo e do manejo dos conceitos nativos (êmicos) que se pode apresentar no plano legal a existência dos assim chamados 'remanescentes de quilombo'.

Em certa medida, e é importante que se frise, o termo quilombo só reaparece como conceito jurídico-formal na Constituição Federal de 1988, através do ADCT 68, indicando aí uma situação processual, pois se demonstra que são remanescentes, isto é, vindos do passado, estão no presente postulando uma situação distinta da sociedade nacional. $\mathrm{O}$ Decreto n. 4.887, que vai regular o artigo 68 do ADCT, dispõe sobre as características necessárias à classificação das comunidades remanescentes de quilombo. E aí se destaca a autoatribuição, a trajetória histórica própria, dotados de relações territoriais específicas, com presunção de ancestralidade negra relacionada com a resistência à opressão histórica sofrida. Para que essa comunidade negra possa reivindicar o título de remanescente de quilombo e faça juz ao reconhecimento legal do seu território, a relação/ mediação com o estudioso que possa decifrar/ identificar os modos pelos quais se fez e se faz na contemporaneidade é primordial. Ora, isto implica a capacidade de operar com as noções, conceitos, técnicas, métodos que permitem à comunidade científica reconhecer o campo da antropologia. E, do mesmo modo, permite transitar entre comunidades de conhecimento ${ }^{6}$.

A PEC 215 vai de encontro a todo esse processo. Ademais, o fato de que a Câmara dos Deputados se dá também poderes para suprimir atos já considerados definitivos, isto é, as terras indígenas e quilombolas já demarcadas, é um retrocesso. Da mesma forma, a Câmara pretende também ter poderes para anular as unidades de conservação e alterar sua tipologia.

\footnotetext{
${ }^{6}$ Ver, dentre outros, Oliveira (1994).
} 
Desse modo, caso seja aprovada, a alteração no texto da Constituição Federal implica a paralisação de todos os processos de homologação de terra e no favorecimento dos interesses do agronegócio, dentre outros interesses.

A PEC 215 tramitou na Câmara dos Deputados e foi arquivada em 2014. Ocorre que, durante a eleição do atual presidente da Câmara, Eduardo Cunha (PMDB-RJ), o deputado em questão conseguiu o apoio da bancada ruralista, acarretando o desarquivamento da PEC. Embora tenha sido levantada a questão de se tratar de procedimento inconstitucional e antirregimental na Câmara, a PEC continua tramitando.

Até o dia 27 de outubro de 2015, encontrou-se em discussão na Câmara dos Deputados, mediante Comissão Especial, presidida pelo deputado ruralista Nilson Leitão (PSDB/MT). No referido dia, houve a votação da PEC em comento, a despeito das tentativas de procrastinar a decisão por parte dos deputados contrários e dos protestos dos índios e quilombolas dentro da Câmara e em vários Estados brasileiros. Os deputados contrários conseguiram prolongar as discussões até o início da votação da ordem do dia no Plenário, o que implicaria o encerramento de todas as discussões das comissões, de acordo com o regimento. Entretanto o presidente da Comissão Especial decidiu apenas suspender a sessão, para reiniciá-la após a votação da ordem do dia no Plenário, o que resultou na votação e aprovação da PEC, por vinte um votos a zero ${ }^{7}$.

Importa mencionar que no dia seguinte, o presidente da Câmara dos Deputados, Eduardo Cunha (PMDB/ RJ), por iniciativa da Frente Parlamentar da Agropecuária (FPA), conhecida como

\footnotetext{
7 Disponível em: <http://camara.leg,br/camaranotícias/noticias/DIREITO-EJUSTICA/498986-COM-PROTESTO-DE_ OPOSITORES,-COMISSAO-APROVA-PECSOBRE-TERRAS-INDIGENAS.html>. Acesso em: 30 out. 2015.
}

bancada ruralista, autorizou a criação de uma Comissão Parlamentar de Inquérito (CPI) para investigar a Fundação Nacional do Índio (FUNAI) e o Incra em processos de demarcação de terras indígenas e quilombolas em todo o país, a partir da revisão dos laudos antropológicos que resultaram ou que possam resultar na demarcação.

Seguindo o procedimento de tramitação, a PEC segue para o Plenário, onde precisa ser aprovada por $60 \%$ dos 513 deputados, em dois turnos. Se aprovada no Plenário da Câmara dos Deputados, passa ao Plenário do Senado, onde, para ser aprovada, necessita também de $60 \%$ dos votos dos senadores, em dois turnos de votação. Caso não alcance esse número de votos, o projeto é arquivado.

Nesse contexto, importa mencionar que quarenta e oito dos oitenta e um senadores da República publicaram um manifesto contra a PEC em comento. Essa iniciativa foi articulada pelo senador João Capiberibe (PSB/AP). No manifesto, os senadores unificaram seu discurso desfavoravelmente à PEC 215, em defesa dos direitos territoriais de povos indígenas e comunidades tradicionais e do meio ambiente.

Ressaltaram que a ratificação de direitos de minorias não pode ficar suscetível a maiorias temporárias. Assim, o ato de demarcação é técnico e declaratório, não havendo sentido em inserir o componente político, não cabendo, portanto, trazer a matéria para o âmbito do Congresso Nacional, importando em um "equívoco político e jurídico, um atentado aos direitos indígenas".

No dia 19 de maio de 2015, na Câmara dos Deputados, organizações e movimentos sociais, indígenas, indigenistas e ambientalistas, junto com as Frentes Parlamentares de Apoio aos Povos Indígenas, em Defesa dos Direitos Humanos e Ambientalista, promoveram a Plenária "Ameaças aos direitos fundamentais e a PEC 215: democracia, povos 
indígenas e meio ambiente". Em junho, publicaram um manifesto no qual repudiam a PEC 215/2000.

No referido manifesto, sustenta-se a inconstitucionalidade da PEC, em razão de clara violação ao princípio da separação de poderes e aos direitos fundamentais dos povos indígenas e quilombolas, que são blindados constitucionalmente, já que consideradas cláusulas pétreas e com respaldo no plano normativo internacional.

Nesse sentido, manifestam pleno apoioaosPovos Indígenas, às Comunidades Quilombolas e à Coletividade brasileira e exigem a retirada imediata de tramitação da PEC 215/2000, com base, dentre outras, nas seguintes razões: a demarcação das Terras Indígenas, a titulação dos Territórios Quilombolas e a criação de Unidades de Conservação da Natureza são atos tipicamente administrativos de caráter estritamente técnico destinados a implementar direitos constitucionais coletivos conquistados no período da Constituinte; os direitos constitucionais coletivos são o resultado do reconhecimento acerca da imprescindibilidade do equilíbrio ecológico para o bem-estar da sociedade e da necessidade de destinar terras aos povos e comunidades que as ocupam tradicionalmente, tanto para garantir sua sobrevivência física e cultural, como para a reparação da dívida histórica do Brasil para com os povos indígenas, quilombolas e comunidades tradicionais.

Além disso, destacam que "a luta dos Povos Originários é uma luta para o bem-estar de toda a sociedade, em defesa da pluralidade da coletividade brasileira e do meio ambiente ecologicamente equilibrado", razão pela qual a biodiversidade, a sustentabilidade e o equilíbrio ambiental não podem ser submetidos aos interesses de maiorias legislativas de ocasião no Congresso Nacional.

Ademais, ressaltam que o deslocamento de competência em matéria constitucional só pode ser feito para ampliar direitos, e não para impor retrocessos, considerando que os Povos Indígenas e Comunidades Quilombolas do Brasil são verdadeiros sujeitos de direito, cidadãos e cidadãs, e, como tais, devem ser respeitados em seus direitos e em sua integridade física, moral, cultural e histórica.

Como se percebe, o objeto da PEC é assunto que afeta diretamente os quilombolas, haja vista que transfere do Poder Executivo para a Câmara dos Deputados a competência de criar e anular demarcações de terras indígenas, quilombolas e unidades de conservação, sem ter consulta prévia, livre e informada dessas populações, violando claramente os direitos já conquistados por essas populações.

Destaca-se, ainda, que apensada à PEC 215, encontra-se a PEC 161/2007 que visa alterar o inciso III do art. 225 e o $\S 4^{\circ}$ do art. 231 da Constituição Federal, e art. 68 do Ato das Disposições Constitucionais Transitórias, estabelecendo que a criação de espaços territoriais a serem especialmente protegidos, a demarcação de terras indígenas e o reconhecimento das áreas remanescentes das comunidades dos quilombos deverão ser feitos por lei. Entretanto, como visto, pelas normas vigentes, a competência para a titulação das terras quilombolas é do Poder Executivo, por intermédio do Incra. Mais uma vez, trata-se de proposta que visa dificultar a efetividade do direito assegurado aos quilombolas no âmbito da Constituição Federal.

Cabe mencionar ainda acerca da Ação Direta de Inconstitucionalidade $n$. 3.239 movida pelo Partido Democratas, que requer a inconstitucionalidade do Decreto n. 4.887/2003, que regulamenta o procedimento para identificação, reconhecimento, delimitação, demarcação e titulação das terras ocupadas por remanescentes das comunidades dos quilombos, previsto no artigo 68 .

Alega o requerente que o referido Decreto viola a esfera reservada à lei, pretendendo regulamentar diretamente, sem supedâneo em lei formal, o art. 68 do ADCT, dispensando a mediação de ins- 
trumento legislativo e dispondo ex novo. Além disso, sustenta que não encontra respaldo no art. 84, VI, da Lei Maior, haja vista que refoge à matéria de que trata o mencionado dispositivo, haja vista que disciplina direitos e deveres entre particulares e a administração pública, define os titulares da propriedade de terras onde se localizavam os quilombos, disciplina procedimentos de desapropriação e, consequentemente, importa aumento de despesa.

A ação se encontra pendente de julgamento no âmbito do Supremo Tribunal Federal. O Relator, Presidente Ministro Cezar Peluso, julgou procedente a ação para declarar a inconstitucionalidade do Decreto n. 4.887/2003, sob o fundamento de que o Decreto não extrai fundamento de validade das Leis federais 7.668/1988 e 9.649/199 e constitui decreto autônomo, credenciado enquanto tal à fiscalização concentrada de constitucionalidade, reconhecendo a inconstitucionalidade formal do Decreto $4.887 / 1993$, por ofensa aos princípios da legalidade e da reserva de lei, ao entendimento de que o art. 68 do ADCT, necessariamente, há de ser complementado por lei em sentido formal. Além disso, considerou materialmente inconstitucionais os arts. $2^{\circ}, \S \S 1^{\circ}, 2^{\circ}$ e $3^{\circ}, 7^{\circ}$, $\S 2^{\circ}, 9^{\circ}, 13$ e 17 do aludido Decreto. Após o voto, modulando os efeitos dessa declaração, nos termos do seu voto, pediu vista dos autos a Senhora Ministra Rosa Weber.

A Senhora Ministra Rosa Weber, por sua vez, julgou improcedente o pedido de declaração de insconstitucionalidade do supracitado Decreto. De acordo com a Ministra, o artigo 68, do ADCT, não é norma veiculadora de preceito genérico, razão pela qual não vislumbra no Decreto conteúdo que já não esteja nele assentado e reforça que:

O objeto do art. 68 do ADCT é o direito dos remanescentes das comunidades dos quilombos de ver reconhecida pelo Estado a sua propriedade sobre as terras por eles histórica e tradicionalmente ocupadas. Tenho por inequívoco tratar-se de norma definidora de direito fundamental de grupo étnico-racial minoritário, dotada, portanto, de eficácia plena e aplicação imediata, e assim exercitável, o direito subjetivo nela assegurado, independentemente de integração legislativa. (STF, 2015, p. 14).

Assim, não visualiza no Decreto mácula aos postulados da reserva de lei e da legalidade, em virtude do que julga improcedente o pedido de inconstitucionalidade formal.

No que se refere aos aspectos materiais, ressalta a Ministra que "homenageia a Constituição o papel protagonizado pelos quilombolas na resistência ao injusto regime escravista, ou escravagista, para os que preferem o galicismo, que por séculos vicejou no Brasil, de panorama bem conhecido" (STF, 2015, p. 23), reconhecendo-os como unidades dotadas de identidade étnico-cultural distintiva, equiparando-os a proteção dispensada aos povos indígenas. Ao final, "reforça que a imperfeição dos resultados alcançados por uma política pública - sob prisma outro que não a de sua constitucionalidade - requer ajuste e aperfeiçoamento, em absoluto a sua paralisação" (STF, 2015, p. 52), ressaltando, portanto, que há deficiências na implementação das políticas públicas relativas aos quilombolas que necessitam, por via de consequência, de melhorias, que não seriam alcançadas caso houvesse o reconhecimento da inconstitucionalidade do Decreto.

Após o voto-vista da Ministra Rosa Weber, pediu vista dos autos o Ministro Dias Toffoli, no dia 25 de março de 2015, e devolveu os autos para julgamento, no dia $1^{\circ}$ de julho de 2015, de acordo com o que se observa no sítio eletrônico, do Supremo Tribunal Federal ${ }^{8}$.

\footnotetext{
${ }^{8}$ Disponível em: <http:/stf.jus.br/portal/processo/verProcessoAndamento.asp? incidente $=2227157>$. Acesso em: 30 out. 2015.
} 


\section{CONSIDERAÇÕES FINAIS}

Observou-se que foi com o advento da Constituição Federal Brasileira de 1988 que se garantiu aos quilombolas o direito à terra, conforme disposição do artigo 68 do Ato das Disposições Constitucionais Transitórias, que foi, sobretudo, resultado de pressões do Movimento Negro, com o objetivo de se estabelecer uma política compensatória para os remanescentes de quilombos.

Constatou-se que, após duas décadas da vigência do artigo 68 , somente cerca de cento e cinquenta e quatro títulos foram emitidos, mesmo havendo um total de aproximadamente três mil comunidades existentes, consoante afirma a Secretaria Especial de Políticas de Promoção da Igualdade Racial.

Além de esse fato implicar, de algum modo, a ineficiência das políticas públicas implementadas pelo Estado no tocante ao reconhecimento desse direito, há, no cenário legislativo, o trâmite da Propostas de Emenda Constitucional n. 215/2000 e 161/2007 e Ação Direta de Inconstitucionalidade n. 3.239 que, caso aprovadas, implicarão em claro retrocesso jurídico à proteção do direito à terra dessas comunidades.

Muitos direitos adquiridos com a Constituição vigente se encontram, portanto, ameaçados. O reconhecimento ao direito à terra das populações quilombolas, a regulamentação do processo de identificação e o reconhecimento e titulação dos territórios são alvo desse retrocesso. Caso seja reconhecida a inconstitucionalidade do Decreto 4.887/2003, o processo de titulação de terras de quilombos será paralisado, por falta de regulamentação. No mesmo sentido, se aprovada a PEC n. 215/2000, dificilmente um território quilombola será reconhecido e titulado.

Nesse cenário, percebe-se que há uma ação por parte de membros do Poder Legislativo que parece contraditar um princípio estabelecido no âmbito do pla- no jurídico, refletindo um conhecimento produzido no campo acadêmico, no qual a diferença surge como elemento central para se pensar a cultura e a identidade. Ora, partindo de Barth (2000), pode-se afirmar que o mais importante não é conceber a identidade como vinculada e dependente de uma quantidade e qualidade de uma cultura. Ao contrário, é na presença e na ação dos grupos, que se constroem e se mantêm as diferenças. Então, historicamente somos constituídos por e pela diferença e a antropologia tem-nos mostrado que as identidades são performadas, discutidas, construídas e (re) significadas, demandando o reconhecimento dos direitos que foram assumidos pela sociedade no momento em que se construiu o marco legal de uma Constituição. E, é nesse plano que tanto o Direito como a Antropologia se mostram como instrumentos capazes de traduzir experiências, demandas e realizações para uma sociedade mais justa, na medida em que se reconheça a sua complexidade.

\section{REFERÊNCIAS}

ALMEIDA, Alfredo W. B. Os quilombos e as novas etnias. In: O'DWYER, Eliane Cantarino (Org.). Quilombos: identidade étnica e territorialidade. Rio de Janeiro: FGV/ABA, 2002.

ARAÚJO, Eulália B.; BATISTA, Mércia R. R. Formas de de pertencer a uma comunidade quilombola: o caso do Monte São Sebastião em Santa Luzia (PB). In: GODÓI, Emília P. de; MENEZES, Marilda A. (Org.). Uma terra para se viver: assentados, colonos e quilombolas. São Paulo: Annablume; Brasília: CNPq, 2013.

ARRUTI, José Maurício A. Mocambo: antropologia e história do processo de formação quilomboa. Bauru, SP: Edusc, 2006.

BARTH, Fredrik. Grupos étnicos e suas fronteiras. In: POUTIGNAT, Philippe ; STREIFF-FENART, Jocelyn. Teorias da etnicidade. São Paulo: Fundação Editora da UNESP, 1997.

. O guru, o iniciador e outras variações antropológicas. Rio de Janeiro: Contra Capa, 2000. 
BATISTA, Mércia R. R. Grilo: das memórias de assujeitado ao direito quilombola. In: BANAL, Alberto ; FORTES, Maria Ester P. (Org.). Quilombos da Paraíba: a realidade de hoje os desafios para o futuro. João Pessoa, PB: Imprell, 2013.

BOURDIEU, Pierre. O poder simbólico. Rio de Janeiro: Bertand Brasil, 2004.

BRASIL. Constituição da República Federativa do Brasil. Disponível em: http:/ / www.planalto. gov.br/ccivil_03/constituicao/constituicao. htm. Acesso em: 10 maio 2015.

BRASIL. Decreto n. 4.887, de 20 de novembro de 2003. Regulamenta o procedimento para identificação, reconhecimento, delimitação, demarcação e titulação das terras ocupadas por remanescentes dascomunidades dosquilombos de que trata o art. 68 do Ato das Disposições Constitucionais Transitórias. Disponível em: <http:/ / www.planalto.gov.br/ccivil_03/_ ato2004-2006/2004/decreto/d5051.htm>. Acesso em: 15. ago. 2015.

CAPIBERIBE, João et al. Senadores apoiam sociedade civil contra a PEC 215. Disponível em: <https://www.socioambiental.org/ sites/blog.socioambiental.org/files/nsa/ arquivos/ccf28052015_00002.pdf>. Acesso em: 15 ago. 2015.

CARDOSO DE OLIVEIRA, Roberto. Identidade, etnia e estrutura social. São Paulo: Pioneira, 1976.

INSTITUTO NACIONAL DE COLONIZAÇÃO E REFORMA AGRÁRIA (INCRA). Instrução Normativa n. 57, de 20 de outubro de 2009. Regulamenta o procedimento para identificação, reconhecimento, delimitação, desintrusão, titulação e registro das terras ocupadas por remanescentes das comunidades dos quilombos de que tratam o art. 68 do Ato das Disposições Constitucionais Transitórias da Constituição Federal de 1988 e o Decreto n. 4.887, de 20 de novembro de 2003. Disponível em: <http:/ / www.incra.gov.br/ sites/default/files/uploads/institucionall/ legislacao--/atos-internos/instrucoes / in_57_2009_quilombolas.pdf>. Acesso em: 4 nov. 2015.

INSTITUTO SOCIOAMBIENTAL. Manifesto público contra a PEC215/2000. 2015. Disponível em: <https://www.socioambiental.org/ sites/blog.socioambiental.org/files/nsa/ arquivos/manifesto_contra_a_pec_215_4. pdf $>$. Acesso em: 10 ago. 2015.

JOB, Luciana. "De quem é este quilombo? (...) Era só o que me faltava!". 2006. Disponível em: <http://cpisp.org.br/acoes/upload/ arquivos / DeQuemeEsteQuilombo_ LucianaJob.pdf>. Acesso em : 9 maio 2015.

MITIDIERI FIGUEIREDO, Leandro C. Remanescentes de quilombos, indios, meio ambiente e segurança nacional: ponderação de interesses constitucionais. 2011. Disponível em: <http:/ / www.cpisp.org.br/acoes/upload/arquivos/ PonderacaodeInteressesConstitucionais_LeandroMitidieri.pdf>. Acesso em: 5 maio 2015.

NASCIMENTO, Germana A. R. do. As comunidades remanescentes de quilombo e o direito aos títulos das terras por elas habitadas. 2011. Monografia (Conclusão de Curso em Ciências Sociais) - Universidade Federal de Campina Grande, PB.

O'DWYER, Eliane C. Quilombos: identidade étnica e territorialidade. Rio de Janeiro: FGV/ ABA, 2002.

OLIVEIRA, João Pacheco de. Os instrumentos de bordo: expectativas e possibilidades do trabalho do antropólogo em Laudos Periciais. In: SILVA, Orlando Sampaio; LUZ, Lídia; HELM, Cecília Maria Vieira. A perícia antropológica em processos judiciais. Florianópolis, SC: Editora da UFSC, 1994.

Uma etnologia dos « índios misturados » ? Situação colonial, territorialização e fluxos culturais. MANA, Rio de Janeiro, v. 4, n. 1, abr. 1998.

SOUZA, Barbara O. Aquilombar-se: panorama historico, identitario e politico do Movimento Quilombola Brasileiro. 2008. Dissertação (Mestrado em Antropologia) - Universidade de Brasília, Brasília, DF.

SUNDFELD, Carlos A. Comunidades Quilombolas: direito à terra. Brasília: Fundação Cultural Palmares/MinC/Editorial Abaré, 2002.

SUPREMO TRIBUNAL FEDERAL (STF). Ação Direta de Inconstitucionalidade 3.239. Voto Ministra Rosa Weber. Distrito Federal , mar. 2015. Disponível em: http://www.stf.jus. br/arquivo/cms/noticiaNoticiaStf/anexo/ ADI3239RW.pdf. Acesso em: 21 out. 2015. 


\section{Sobre os autores :}

Germana Aguiar Ribeiro do Nascimento: Bacharel em Direito pela Universidade Estadual da Paraíba. Bacharel em Ciências Sociais pela Universidade Federal de Campina Grande (UFCG), PB. Mestre em Direitos Humanos pela Université Catholique de Lyon - França (reconhecido pela Universidade Federal da Paraíba). Doutoranda em Derechos Humanos, Democracia y Justicia Internacional pela Universidad de Valencia. E-mail: germana_aguiar@hotmail.fr

Mércia Rejane Rangel Batista: Doutora em Antropologia Social, pela Universidade Federal do Rio de Janeiro (UFRJ). Professora Adjunta da Universidade Federal de Campina Grande (UFCG), PB. E-mail: mercia.batista1@gmail.com

Marilia Aguiar Ribeiro do Nascimento: Mestranda em Direitos Fundamentais, pela Universidade de Lisboa - Portugal. Professora das Faculdades Integradas de Patos (FIP), PB. E-mail: mariliaarn@hotmail.com 